\title{
PRESENCE AND RISK FACTORS OF METABOLIC SYNDROME DETERMINANTS IN INDIAN OBESE CHILDREN AND ADOLESCENTS: ACCORDING TO NATIONAL CHOLESTEROL EDUCATION PROGRAM (NCEP) (ATPIII) CRITERIA
}

\section{Kulshrestha Himani1.,*Gupta Vani1․, Gupta Vandana²,, Mishra Supriya1 and Mishra Sameeksha1}

\author{
${ }^{1}$ Department of Physiology, King George's Medical University, Lucknow, India \\ 2Department of Obstetrics and Gynecology, RIMS, Uttar Pradesh University of Medical Sciences, \\ SaifaiEtawah, India \\ DOI: http://dx.doi.org/10.24327/ijrsr.2017.0803.0093
}

\begin{tabular}{l}
\hline ARTICLE INFO \\
\hline Article History: \\
Received $06^{\text {th }}$ December, 2015 \\
Received in revised form $14^{\text {th }}$ \\
January, 2017 \\
Accepted $23^{\text {rd }}$ February, 2017 \\
Published online $28^{\text {th }}$ March, 2017 \\
\hline
\end{tabular}

Key Words:

Childhood obesity, metabolic syndrome, BMI percentile, NCEP ATP III

\begin{abstract}
The present study was performed to determine the presence and risk factors of metabolic syndrome (MS) determinants in Indian obese children and adolescents. The study included 220 obese children and adolescents (body mass index $[\mathrm{BMI}] \geq 84^{\text {th }}$ percentile) aged between $5-11$ years(children) and 1217 years(adolescents). The diagnosis of MS was made according to the criteria adapted from the National Cholesterol Education Program Adult Treatment Panel III (NCEP ATP III) guidelines. BMI percentiles were calculated to assess the degree of obesity. The prevalence of MS and risk factors were determined. Quantitative variables were determined using unpaired t-test between two groups and ANOVA test between three groups. Qualitative variables were compared by using chisquare test or fisher's exact test as appropriate. The prevalence of MS in male was (56.09\%) higher than female (53.62\%). The age at onset of obesity, sedentary life-style in patients with MS, all laboratory values (fasting plasma glucose, lipid profile: triglyceride (TG) and very-low-density lipoprotein (VLDL-C), were higher in patients with MS than without MS and were statistically significant $(p<0.001)$ except LDL-C,HDL-C and total cholesterol(TC),in which mean value is slightly differentiate in patients with MS but are not statistically significant and the number of actively spent hours were lower in cases with MS. The most important determinant of MS was BMI percentile $(\mathrm{p}<0.001)$. A one-point increase in BMI percentile increased the prevalence of MS in group having more than two metabolic risk factors $(51.66 \%)$ in comparison to the prevalence of MS in more than three metabolic risk factors $(35 \%)$ and more than four metabolic risk factors $(13.33 \%)$ respectively but there was no significant difference observed $(\mathrm{p}>0.05)$. The results from this study indicate that, although should be replace by because the correlation between MS and BMI percentile were strong, so the BMI percentile still may be an effective parameter in identification of obese Indian children and adolescents who are at risk for MS. Screening of the patients with BMI percentile $\geq 85$ for MS is important for establishing an early diagnosis.
\end{abstract}

Copyright (1) Gupta Vani et al, 2017, this is an open-access article distributed under the terms of the Creative Commons Attribution License, which permits unrestricted use, distribution and reproduction in any medium, provided the original work is properly cited.

\section{INTRODUCTION}

The metabolic syndrome (MS) is a cluster of glucose intolerance, central obesity, hypertension, dyslipidemia and is associated with a higher incidence of metabolic risk factors events in adult life and mortality. The pathophysiology of the MS has not been elucidated in children. Obesity is a serious disease associated with behavioral, environmental, eating habitat and also affected by genetic susceptibility. In children obesity is also a result of imbalance between food intake and low energy expenditure. Obesity plays a potential impact on many metabolic related diseases. In children, several competing definitions of metabolic syndrome are in use and each is differently linked to BMI (percentile or z-score). These definitions include that of the National Cholesterol Education Program (NCEP) Adult Treatment Panel Third (ATP III) (Grundy et al. 2005), the International Diabetes Federation (IDF) (Alberti et al.2006) and the Institute for clinical system improvement (ICSI). The ICSI definition requires the BMI plus any two other metabolic traits. But NCEP ATP III and IDF definitions require at least three metabolic including BMI (percentile). In studies of ATP III metabolic syndrome, as

*Corresponding author:Gupta Vani

Department of Physiology, King George's Medical University, Lucknow, India 
many as half of patients have increased BMI (Lion et al.2004, Cheal KL et al. 2004, Meigset al.2006).

From many of the guideline ATP III or IDF metabolic syndrome definitions identify patients with abnormal BMI (Rathmannet al.2006). The metabolic syndrome also called X syndrome. Many chronic diseases are developed with metabolic syndrome. Obesity in the early childhood is the main cause of hyperlipidimia later in life.

The sedentary lifestyle and increasing obesity is main cause of increasing metabolic syndrome in children worldwide. The chronic diseases are a growing problem for developing countries which ignored health strategies (Kelishadiet al. 2007).

There is no genetic prevision to support, but actually white people and African-Americans people are more predict for obesity and metabolic syndrome, whereas Africans, Arabic and Asiatic race are less commonly affected. The reason behind it, the cultural differences, economical disadvantages and lifestyle behaviors for the development of obesity-related diseases and disease outcomes. In last 20 years, the rates of obesity are increasingly in developed and developing countries (Whitaker et al.2006, Boardman et al. 2005, White et al.2004).

In adults, the metabolic syndrome defined according to NCEPATP III cut point, such as 3 or more factors from the following: abnormalities in waist circumference, fasting blood glucose level, triglyceride level, high density lipoprotein cholesterol level, systolic blood pressure (Bethesda et al.2001), but in children no any guideline is present to define metabolic risk factors.

In the current study, we determined the MS and risk factors in children and adolescents according to the criteria adapted from the National Cholesterol Education Program Adult Treatment Panel III (NCEP ATP III) guidelines (Yasaret al.2008). BMI percentile and $z$-scores were calculated to assess the degree of obesity. The most important determinant of MS was abnormal BMI percentile or $z-$ scores. The Metabolic syndrome was considered if three or more of the following criteria were present in obese children: elevated triglyceride reduced HDL, elevated systolic blood pressure and elevated fasting blood glucose.

The absence of guideline for MS in children and adolescent's studies in our country as in other poor countries, make interesting to design the current study about this emerging problem in comparison with other countries.

The objective of our study was to determine the presence of MS determinants in Indian obese children and adolescents according to NCEP ATP III criteria.

\section{MATERIALS AND METHODS}

\section{Patient's selection and methods}

A total of 220 obese children ( 82 males and 138 femalesof aged 5-11 years and 12-17 years) referred to the Department of Physiology, K.G.M.U., between oct 2011 to sep 2014 were enrolled in our study. From them few were selected by conducting obesity awareness camps in schools of Lucknow District. The age and gender adjusted body mass index
$(\mathrm{BMI}) \geq 85$ th percentile (according to National Cholesterol Education Program (NCEP-ATP III) were enrolled in the study(Yasaret al. 2008). Patients with obesity secondary to endocrinological, genetic diseases, having any viral/bacterial infection, any respiratory/inflammatory diseases or other systemic diseases and pharmacological agents, as well as those on medication were excluded from the study. Informed consent was obtained from all children and their families during enrollment.

Information about the level of their physical activity or outdoor activity including level of daily activities such as pattern of nutrition, time spent indoors watching TV, using computers, playing computer and video games, sleeping hours and studying time was recorded using a self-reporting questionnaire. Age at onset of obesity was also assessed.

Family history of obesity, hypertension (HT), diabetes mellitus (DM), dyslipidemia (DL) and educational status of the parents were recorded. The study protocol was previously reviewed and approved by the ethics and research committee of the King George Medical University Lucknow.

The height and weight were measured in the first visit of patient, calculating the body mass index (BMI) according to the formula (weight in kilograms divided by the square of the height in meters). Additionally, waist circumference was also calculated. The degree of obesity was determined usingBMI percentile or z-scores. The BMI percentile and z-score was calculated by online BMI-for-age CDC software with theLambda, Mu, Sigma (LMS) method (Cole et al. 2000, Cole et al. 1995, Garrowet al. 1981) and thepatients were divided into four groups according to their percentile 5-84, 85-94, 9598 and $>98$ or $z$-scores between $1.65-1.99,2-2.49,2.50-2.99$ and $\geq 3$ were considered to reflect healthy weight or without metabolic syndrome, overweight, obese, severally obese respectively. Blood pressure was measuredby a manometer with an appropriate cuff on the rightarm after 5 min of rest and the values were compared withstandard percentiles for age and gender (Tumeret al. 1999).

The fasting plasma glucose was performed after a 12-h fast, glucose levels was measured in blood samples. Lipid profiles [(triglyceride (TG), total cholesterol (TC), high-density lipoprotein-cholesterol (HDL-C), low-density lipoproteincholesterol (LDL-C), and very-low-density lipoproteincholesterol (VLDL-C)] were determined in the fasting blood samples. Plasma glucose levels were measured with the enzymatic colorimetric method GOD-PAP. Lipid profile was measured by enzymatic method (Randox Laboratories Ltd., Antrim, UK) and LDL and VLDL calculated by Friedewald formula. (Friedewald et al.1972)

VLDL $=$ Triglyceride $/ 5$

LDL-Cholesterol $=$ Total Cholesterol- $($ HDL-C + VLDL)

For the diagnosis of MS, the presence of at least three of the following criteria (in accordance with National Cholesterol Education Program Adult Treatment Panel III [NCEP ATP III] recommendations) was required. These criteria include (Abate et al. 2000, Cameron et al. 2004, Keskin et al 2005, Molnar et al. 2004, Viner et al.2005) 
1. Overweight: BMI $85-94^{\text {th }}$ percentile, obese BMI: $95-98^{\text {th }}$ percentile, severally obese BMI: $>98^{\text {th }}$ percentile $(2-20$ years, Centers for Disease Control and Prevention [CDC] growth charts, United States) (Viner et al. 2005)

2. Abnormal glucose homeostasis: the presence of the following:

Elevated fasting glucose (EFG): $\mathrm{FG} \geq 100 \mathrm{mg} / \mathrm{dl}$

3. Hypertension: systolic/diastolic blood pressure $\geq 90^{\text {th }}$ percentile for age and sex or elevated systolic BP $\geq 130$ $\mathrm{mm}$ of $\mathrm{Hg} /$ diastolic $\mathrm{BP} \geq 85 \mathrm{~mm}$ of $\mathrm{Hg}$

4. Dyslipidemia: presence of one of the following (Vineret al.2005):

a. High TG ( $\geq 90$ th percentile for age and sex) or $\geq 150 \mathrm{~mm}$ of $\mathrm{Hg}$

b. Low HDL-C levels ( $<5$ th percentile for age and sex) or $<$ $40 \mathrm{mg} / \mathrm{dl}$ in male children and $<50 \mathrm{mg} / \mathrm{dl}$ in female children

c. LDL-C ( $\geq 95$ th percentile for age and sex) or $\leq 40$ $\mathrm{mg} / \mathrm{dlLDL}-\mathrm{Cholesterol}=$ Total Cholesterol- $($ HDL-C + VLDL)

\section{Statistical analysis}

Categorical variables are presented in number and percentage (\%) and continuous variables are presented as mean and Standard Deviation. Quantitative variables were compared using unpaired t-test between two groups and ANOVA test between three groups. Qualitative variables were compared using Chi-Square test /Fisher's exact test as appropriate. A p value of $<0.05$ was considered statistically significant. The data was entered in MS EXCEL spreadsheet and analysis was done using Statistical Package for Social Sciences (SPSS) version 21.0.

\section{RESULTS}

A total of 468 pediatric patients visits were performed between Oct 2011 to Sep 2014 finding 220 patients with the diagnosis of obesity. From them total number of obese with MS cases were found $120(54.5 \%)$ and non-MS but obese cases were $100(45.5 \%)$. From them, the male patients were 82 and females were 138. The prevalence of MS in male was higher (56.09 $\%)$ than in female(53.62\%). (Table 1 ).

Table 1 Gender based data of population study, divided into two subgroups with and without metabolic syndrome

\begin{tabular}{cccc}
\hline Gender & Without MS & With MS & Total \\
\hline Male & $36(36 \%)$ & $46(38.3 \%)$ & $82(37.3 \%)$ \\
Female & $64(64 \%)$ & $74(61.7 \%)$ & $138(62.7 \%)$ \\
Total & $100(100 \%)$ & $120(100 \%)$ & $220(100 \%)$ \\
\hline
\end{tabular}

The patients were divided into two groups according to age: (a) 5-11 years (b) 12-17 years. The prevalence of MS was higher in age group of 5-11 years than age group of 12-17 years. (Table 2)

Table 2

\begin{tabular}{ccccc}
\hline & & Male & Female & Total \\
\hline \multirow{3}{*}{ With MS } & \multirow{2}{*}{ 5 to 11 years } & 23 & 42 & 65 \\
Cases & & $50.00 \%$ & $56.80 \%$ & $54.20 \%$ \\
& \multirow{2}{*}{12 to 17 years } & 23 & 32 & 55 \\
& & $50.00 \%$ & $43.20 \%$ & $45.80 \%$ \\
Without MS & 5 to 11 years & 20 & 29 & 49 \\
cases & & $55.60 \%$ & $46.00 \%$ & $49.50 \%$ \\
& \multirow{2}{*}{12 to 17 years } & 16 & 34 & 50 \\
& & $44.40 \%$ & $54.00 \%$ & $50.50 \%$ \\
\hline
\end{tabular}

The BMI in percentile and BMI z-scores were $94.66 \pm 4.08$ and $1.80 \pm 0.58$ respectively in MS cases was higher than patients without MS (BMI in percentile $54.75 \pm 12.67$ and BMI in zscore $0.14 \pm 0.35)$ and are statistically significant $(\mathrm{p}<0.001)$ Table(3)

It showed the mean distribution of clinical characteristics of patients. Higher mean of chronologic age, body weight, height, BMI percentile, BMI z-score, average systolic and diastolic blood pressures was found in with MS group compared to non MS group and found statistically significant difference $(\mathrm{p}<0.001)$ (Table 3).

Table 3clinical data of the population study, divided into two subgroups with and without metabolic syndrome

\begin{tabular}{|c|c|c|c|}
\hline Characteristics & $\begin{array}{c}\text { Without MS } \\
(n=100) \\
(45.45 \%) \\
\end{array}$ & $\begin{array}{c}\text { With MS }(\mathrm{n}=120) \\
\quad(54.54 \%)\end{array}$ & P Value \\
\hline Weight (Kg) & $37.96 \pm 9.54$ & $44.98 \pm 12.45$ & $<0.001$ \\
\hline Height $(\mathrm{cm})$ & $144.19 \pm 13.87$ & $133.54 \pm 16.21$ & $<0.001$ \\
\hline $\mathrm{BMI}\left(\mathrm{Kg} / \mathrm{m}^{*} \mathrm{~m}\right)$ & $17.88 \pm 1.34$ & $24.85 \pm 3.49$ & $<0.001$ \\
\hline BMI (Percentile) & $54.75 \pm 12.67$ & $94.66 \pm 4.08$ & $<0.001$ \\
\hline BMI z-score & $0.14 \pm 0.35$ & $1.80 \pm 0.58$ & $<0.001$ \\
\hline Waist circumference $(\mathrm{cm})$ & $74.26 \pm 7.81$ & $78.59 \pm 8.10$ & $<0.001$ \\
\hline Systolic BP & $105.83 \pm 9.53$ & $114.88 \pm 7.29$ & $<0.001$ \\
\hline Diastolic BP & $68.32 \pm 7.14$ & $77.16 \pm 5.66$ & $<0.001$ \\
\hline
\end{tabular}

$\mathrm{MS}=$ metabolic syndrome; $\mathrm{M}=$ male; $\mathrm{F}=$ female; $\mathrm{BMI}=$ body mass index. Values are mean \pm SD.

In patients with MS, all laboratory values (fasting plasma glucose, lipid profile TG and VLDL-C), were higher in patients with MS than without MS and were statistically significant $(p<0.001)$ except LDL-C,HDL-C and total cholesterol(TC), in which mean value is slightly differentiate in patients with MS but are not statistically significant(Table 4).

Table 4 Plasma glucose and lipids of the population study, divided into two subgroups with and without MS

\begin{tabular}{cccc}
\hline $\begin{array}{c}\text { Biochemical } \\
\text { characteristics }\end{array}$ & $\begin{array}{c}\text { Without } \\
\text { MS(n=100) }\end{array}$ & $\begin{array}{c}\text { With } \\
\text { MS(n=120) }\end{array}$ & p-value \\
\hline Fasting glucose, $\mathrm{mg} / \mathrm{dl}$ & $107.42 \pm 4.45$ & $115.02 \pm 12.51$ & $<0.001^{*}$ \\
Blood Glucose(PP) & $151.03 \pm 15.40$ & $145.96 \pm 3.13$ & $0.001^{*}$ \\
Triglycerides (mg/dl) & $103.09 \pm 13.86$ & $114.63 \pm 9.86$ & $<0.001^{*}$ \\
LDL-cholesterol (mg/dl) & $121.19 \pm 7.99$ & $122.83 \pm 24.23$ & 0.517 \\
HDL-cholesterol (mg/dl) & $42.59 \pm 4.09$ & $42.66 \pm 6.12$ & 0.919 \\
VLDL-cholesterol & $20.6182 \pm 2.77$ & $23.0975 \pm 0.72$ & $<0.001$ \\
$\begin{array}{c}\text { (mg/dl) } \\
\text { Total cholesterol (mg/dl) }\end{array}$ & $184.80 \pm 7.71$ & $188.51 \pm 24.88$ & 0.153 \\
\hline
\end{tabular}

MS=metabolic syndrome; HOMA-IR=homeostasis model assessment of insulin resistance; LDL=low-density lipoprotein; $\mathrm{HDL}=$ high-density lipoprotein;

$\mathrm{VLDL}=$ very-low-density lipoprotein. Values are mean $\pm \mathrm{SD}$

The prevalence of obesity was $(54.1 \%)$, fasting blood glucose (100\%), elevated TG $(99.1 \%)$ and elevated blood pressure $(1.6 \%)$ was found higher but the HDL was reduced $(34.1 \%)$ in all the patients of with MS compare with without MS. (Table $5)$.

The patients with metabolic risk factors were categorized into three groups. In group $\mathrm{I}^{\text {st }}$ overweight patients have higher prevalence $(40 \%)$ of developing metabolic risk factors than that of patients in group II (35\%) and group III (25\%) respectively. Overall the prevalence of developing metabolic risk factors was higher in patients having two metabolic risk factors but is not statistically significant. (Table 6). 
Table 5 Distribution of metabolic risk factors of the population study, divided into two subgroups with and without MS

\begin{tabular}{|c|c|c|}
\hline Metabolic risk factors & Without MS $(n=100)$ & $\begin{array}{l}\text { With MS } \\
(n=120)\end{array}$ \\
\hline $\begin{array}{l}\text { Obesity: BMI percentile } \\
\text { or z-score }\end{array}$ & $4(4 \%)$ & $65(54.1 \%)$ \\
\hline $\begin{array}{c}\text { Abnormal glucose } \\
\text { homeostasis or fasting } \\
\text { glucose }\end{array}$ & $88(88 \%)$ & $120(100 \%)$ \\
\hline $\begin{array}{ll} & \text { Dyslipidemia } \\
\text { a. } & \text { Elevated TG } \\
\text { b. } & \text { Reduced HDL }\end{array}$ & $\begin{array}{ll}\text { a. } & 33(33 \%) \\
\text { b. } & 2(2 \%)\end{array}$ & $\begin{array}{l}\text { (a) } 119(99.1 \%) \\
\text { (b) } 41(34.1 \%)\end{array}$ \\
\hline $\begin{array}{c}\text { Hypertension or elevated } \\
\text { systolic BP }\end{array}$ & $1(1 \%)$ & $2(1.6 \%)$ \\
\hline
\end{tabular}
assessment. Results are expressed as n (\%).

Table 6 Number of metabolic risk factors of population study, categorized according to BMI (percentile)

\begin{tabular}{|c|c|c|c|c|c|}
\hline $\begin{array}{c}\text { BMI } \\
\text { (percentile) }\end{array}$ & $\begin{array}{c}\text { Group I (85- } \\
94)(n=48) \\
(40 \%)\end{array}$ & $\begin{array}{c}\text { Group II (95- } \\
\text { 98) }(\mathrm{n}=42) \\
(35 \%)\end{array}$ & $\begin{array}{c}\text { Group III } \\
(>98)(n=30) \\
(25 \%)\end{array}$ & Total & $\begin{array}{c}\text { P- } \\
\text { Value }\end{array}$ \\
\hline $\begin{array}{l}+4 \text { Metabolic } \\
\text { risk factors }\end{array}$ & $5(10.41 \%)$ & $7(16.66 \%)$ & $4(13.33 \%)$ & $16(13.33 \%)$ & 0.684 \\
\hline $\begin{array}{c}+3 \text { Metabolic } \\
\text { risk factors }\end{array}$ & $20(41.66 \%)$ & $14(33.33 \%)$ & $8(26.66 \%)$ & $42(35 \%)$ & 0.385 \\
\hline $\begin{array}{l}+2 \text { Metabolic } \\
\text { risk factors }\end{array}$ & $23(47.91 \%)$ & $21(50 \%)$ & $18(60 \%)$ & $62(51.66 \%)$ & 0.562 \\
\hline
\end{tabular}

$\mathrm{BMI}=$ Body mass index. Result are expressed as $\mathrm{n}$

Among various parameters that may influence the risk of MS (i.e., obesity, BMI percentile, elevated TG, fasting glucose, reduced HDL), the most important determinant of MS was the BMI percentile $(p<0.001)$. A one-point increase in BMI percentile increased the prevalence of MS in group having more than two metabolic risk factors $(51.66 \%)$ in comparison to the prevalence of MS in more than three metabolic risk factors (35\%) and more than four metabolic risk factors $(13.33 \%)$ respectively but there was no significantly difference observed $(\mathrm{p}>0.05)$ (Table 6)

\section{DISCUSSION}

The lack of previous studies about metabolic syndrome in Indian children makes it interesting to know the actual situation in one of the developing country in Asia. The numbers of patients were not the ideal to try to show the prevalence in the entire country, but it would be an initial point for future studies. The prevalence of MS is reported to be 30-50\% among obese children (CDC 2000, WHO 1980). Many more studies are tremendous increase on obesity and MS in children; but the results are conflicting (Hanson et al. 2000, Cook et al.2003) because of the lack of consensus on the diagnostic criteria of MS in children and adolescents. In addition to the previous attempts, there is now greater consensus regarding the components of MS during childhood and adolescence. These should include central obesity, insulin resistance, glucose intolerance, hypertension and dyslipidemia (Weiss et al.2004). However, this new definition using age-specific cutoffs has not yet resolved the issue completely and it is suggested that MS should not be diagnosed in children younger than 10 years (Weiss et al.2004).
There are no clear definition for metabolic syndrome in children and adolescents, existing different criteria used according to the place or population of the study. (Lambert et al. 2004, Csabi et al. 2000, Cruz et al. 2004, Agirbasli et al.2006, Esmaillzadeh et al 2006). NCEP-ATP III definition with BMI cut-off values for youths was considered for the diagnosis of metabolic syndrome in the current study.

Regional studies from our country suggest a prevalence of 20$27.2 \%$ for MS in obese children and adolescents (Atabek et al.2006, Yasar et al.2008). However, potential factors that may affect the development of MS have not been analyzed in these studies.

In the current study, the prevalence of MS was $54.5 \%$ in an obese population admitted to a university clinic. This result suggests that MS has become a serious problem in our country. In the literature, there are diverse statements on the impact of gender and puberty on the prevalence of MS (Atabek et al 2006, Cruz et al. 2004). Cruz et al, reported a higher prevalence of MS and its components in male compared to female children. It is also reported that the prevalence of MS may be higher in pubertal patients (Atabek et al. 2006). However, we found that the prevalence of MS is more in patients of prepubertal age 5-11 years group (54.16\%) rather than subjects of pubertal age group 12-17 years (45.83\%). Prevalence in our study was higher in male $(56.09 \%)$ rather than female $(53.62 \%)$.

Although the eating habits of children and adolescents contribute significantly to the development of obesity, they do not have a similar effect on MS (Smith et al. 2004). In the current study, fast-food eating habits and indoor activities had effect on the development of MS. Patients with MS spent a shorter time on daily activities, or they spent more time on sedentary life activities, such as studying and playing computer and video games in comparison to children without MS. The results of this study demonstrate the adverse effect of sedentary lifestyle on the development of MS. However, since this data rely on information obtained through self-reporting questionnaires, it may not be absolutely reliable.

When family medical histories of both groups were analyzed, the prevalence of diabetes, cardiovascular disease and its risk factors were higher in the families of patients with MS comparable without MS.

Csábiet al.'s demonstrated that lower numbers of risk factors have low effect on duration of obesity than in patients with three or four CV risk factors (Csábiet al 2000), but there was no correlation between the duration of obesity and MS. Still, higher mean chronologic age in patients with MS in their study may support the hypothesis that some time is required for the underlying pathologies to take effect (Viner et al.2005).

In contrast Viner et al. demonstrated that development of MS is not effected by the genetic characteristics and presence of MS in the family (Viner et al.2005, Freeman et al. 2002). Our results are also similar that of Viner et al.

Our results on the prevalence of DL and HT are similar to that of Yasar et al 2008 on children and adolescents. However, they reported a higher prevalence of DL and HT in male, whereas there were no patients with type 2 diabetes. The prevalence of 
DL, HT in the current study is comparable more into a previous study from our country (Kelishadiet al. 2007). We found a higher prevalence of MS (54.5\%). In a study by Viner et al. (2005), the prevalence of DL, HT were $30 \%$ and $32 \%$, respectively, while type $2 \mathrm{DM}$ was not observed in any patient (Maitra et al.2004).

The metabolic syndrome was found in 54.5\% of studied patients, with a slightly predilection in males with statistical significance $(p=0.001)$. Lipidic abnormalities account for most of the criteria of metabolic syndrome definition. High blood pressure and high blood glucose have also affected MS in current investigation as expected in comparison with another studies.

In pigmented races, acanthosis Nigerians (AN) is an important early manifestation of the obesity syndrome. AN helpidentifies persons at particular risk of developing the obesity syndrome, dyslipidemia, hypertension. Recognition of AN, therefore, offers important opportunities for health screening and preventative medicine. (Weiss et al.2004).

The prevalence of metabolic risk factors in obese children can change because of varying diagnostic criteria and cut-off values used in different studies (Cruz et al. 2004, Csabiet al. 2000). Viner et al.'s in 2005 reported, the prevalence of the presence of two risk factors in obese children, aged 2-18 years, was $36 \%$, while the prevalence of patients with three and four risk factors were $28 \%$ and $5 \%$, respectively. In our patient group, the prevalence of children with two metabolic risk factors was $51.66 \%$, while with three and four risk factors were found to be $35 \%$ and $13.33 \%$, respectively. Therefore, our results are similar to those of the study by Viner et al,2005. It is stated that an increase in the severity of obesity is not results in deterioration of each component of MS, but it increases its prevalence as well (Viner et al.2005). Similarly, in our study, the prevalence of MS increased significantly in parallel to the severity of obesity.

In the current study, the most important parameter indicating the presence of MS was the BMI percentile. However, the correlation between MS and the BMI percentile was weak, suggesting possible role(s) of other factors. The risk of developing $\mathrm{MS}$ is higher in patients with BMI percentile between 85-94. When compared to those with BMI percentile between 5 and 84.Our results are in good support with the statement of Weiss et al 2004, who expressed that the risk of MS among obese children and adolescents increased, by $50 \%$ with a 0.5 -unit increment in the BMI percentile.

\section{CONCLUSION}

In summary, the prevalence of MS among obese children and adolescents referred to our department during the study period showed a tendency to increase compared to previous studies from Turkey, reaching levels as high as those reported from Europe and the US. Our results also indicate that the BMI percentile still may be an effective parameter in identifying obese children and adolescents who are at risk for MS and screening the patients with BMI percentile for MS may provide an opportunity to establish early diagnosis criteria in obese children and adolescents. However, as suggested, since the correlation between MS and the BMI percentile is strong, further studies should be conducted to reveal other factors that may be responsible for identification of the presence of MS in children and adolescents.

\section{Acknowledgements}

We would like to thank faculty and staff of the Department of Physiology, King George's Medical University, Lucknow for supporting our study.

\section{References}

Abate N (2000) Obesity and cardiovascular disease. Pathogenetic role of the metabolic syndrome and therapeuticimplications. J Diabetes Complications 14:154174.

Agirbasli M, Cakir S, Ozme S, Ciliv G,(2006). Metabolic syndrome in Turkish children and adolescents. Metabolism, 55:1002-6.

Alberti KG, Zimmet P, Shaw J, (2006). Metabolic syndrome: a new world-wide definition: a consensus statement from the International Diabetes Federation. Diabet Med, 23: 469-480.

Atabek ME, Pirgon O, Kurtoglu S, (2006). Prevalence of metabolic syndrome in obese Turkish children and adolescents. Diabetes Res ClinPract, 72:315-321.

Bethesda, MD (2001).National Cholesterol Education Program Expert Panel on Detection, Evaluation, and Treatment of High Blood Cholesterol in Adults (Adult Treatment Panel III): Third report of the National Cholesterol Education Program Expert Panel on Detection, Evaluation, and Treatment of High Blood Cholesterol in Adults (Adult Treatment Panel III).National Institutes of Health.

Bloomgarden ZT, (2004). Definitions of the insulin resistance syndrome: the 1st World Congress on the Insulin Resistance Syndrome. Diabetes Care, 27:824-830.

Boardman JD, Saint Onge JM, Rogers RG, Denney JT, (2005). Race differentials in obesity: the impact of place. $J$ Health SocBehav, 46(3):229-43.

Cameron AJ, Shaw JE, Zimmet PZ, (2004). The metabolic syndrome: prevalence in worldwide populations. EndocrinolMetabClin North Am, 33:351-375.

Centers for Disease Control and Prevention/National Center for Health Statistics (CDC/NCHS) (2000) CDC growth charts: United States.

Cheal KL, Abbasi F, Lamendola C, McLaughlin T, Reaven GM, Ford ES, (2004). Relationship to insulin resistance of the Adult Treatment Panel III diagnostic criteria for identification of the metabolic syndrome. Diabetes, 53:1195-1200. 
Cole TJ, Bellizzi MC, Flegal KM, Dietz WH, (2000). Establishing a standard definition for child overweight and obesity worldwide: international survey. $B M J, 320: 1240-$ 1243.

Cole TJ, Freeman JV, Preece MA, (1995). Body mass index reference curves for the UK. Arch Dis Child, 73: 25-29.

Cook S, Weitzman M, Auinger P, Nguyen M, Dietz WH, (2003). Prevalence of a metabolic syndrome phenotype in adolescents: findings from the third National Health and Nutrition Examination Survey, 1988-1994. Arch PediatrAdolesc Med, 157:821- 827.

Cruz ML, Weigensberg MJ, Huang TT, Ball G, Shaibi GQ, Goran MI, (2004). The metabolic syndrome in overweight Hispanic youth and the role of insulin sensitivity. $J$ ClinEndocrinolMetab, 89:108-113.

Csábi G, Török K, Jeges S, Molnár D, (2000). Presence of metabolic cardiovascular syndrome in obese children. Eur J Pediatr, 159:91-94.

Esmaillzadeh A, Mirmiran P, Azadbakht L, Etemadi A, Azizi F,(2006). High prevalence of the metabolic syndrome in Iranian adolescents. Obesity (Silver Spring), 14:377-82.

Freeman MS, Mansfield MW, Barrett JH, Grant PJ, (2002).Heritability of features of the insulin resistance syndrome in a community-based study of healthy families. Diabet Med, 19:994-999.

Friedewald WT, Levy RI, Fredrickson DS, (1972). Estimation of the concentration low density lipoprotein-cholesterol in plasma, without use of the preparative ultracentrifuge. ClinChem, 18 (6): 499-502.

Garrow JS, (1981). Treat obesity seriously: a clinical manual. Churchill Livingstone, Edinburgh, UK.

Grundy SM, Cleeman JI, Daniels SR, Donato KA, Eckel RH, Franklin BA, Gordon DJ, Krauss RM, Savage PJ, Smith SC Jr, Spertus JA, Costa F, (2005). American Heart Association, National Heart, Lung and Blood Institute: Diagnosis and management of the metabolic syndrome: an American Heart Association/National Heart, Lung, and Blood Institute Scientific Statement.Circulation, 112:2735-2752.

Kelishadi R, (2007). Childhood overweight, obesity and the metabolic syndrome in developing countries. Epidemiol Rev, 29:62-76.

Keskin M, Kurtoglu S, Kendirci M, Atabek ME, Azoic C, (2005). Homeostasis model assessment is more reliable than the fasting glucose/insulin ratio and quantitative insulin sensitivity check index for assessing insulin resistance among obese children and adolescents. Pediatrics, 115:500-503.

Lambert M, Paradis G, O'Loughlin J, Delvin EE, Hanley JA, Levy E,(2004). Insulin resistance syndrome in a representative sample of children and adolescents from Quebec, Canada. Int J ObesRelatMetabDisord, 28:833-41.
Liao Y, Kwon S, Shaughnessy S, Wallace P, Hutto A, Jenkins AJ, Klein RL, Garvey WT, (2004). Critical evaluation of adult treatment panel III criteria in identifying insulin resistance with dyslipidemia. Diabetes Care, 27:978 -983.

Maitra SK, Rowland Payne CM, (2004). The obesity syndrome and acanthosis nigricans. Acanthosis nigricans is a common cosmetic problem providing epidemiological clues to the obesity syndrome, the insulin-resistance syndrome, the thrifty metabolism metabolism, dyslipidemia, hypertension and diabetes mellitus type II. $J$ CosmetDermatol, 3(4):202-10.

Margoth Caceres, Carlos G Teran, Susana Rodriguez and Marcos Medina,(2008). Prevalence of insulin resistance and its association with metabolic syndrome criteria among Bolivian children and adolescents with obesity. BMC Pediatrics, 8(31): 1-6.

Meigs JB, Wilson PW, Fox CS, Vasan RS, Nathan DM, Sullivan L, D’Agostino RB (2006). Body mass index, metabolic syndrome and risk of type 2 diabetes or cardiovascular disease. ClinEndocrinolMetab, 91: 29062912.

Molnár D, (2004). The prevalence of the metabolic syndrome and type 2 diabetes mellitus in children and adolescents. Int J ObesRelatMetabDisord, 28(3): 70-74.

Molnár D, (2004). The prevalence of the metabolic syndrome and type 2 diabetes mellitus in children and adolescents. Int J ObesRelatMetabDisord, 28(3):S70-S74.

Rathmann W, Hastert B, Icks A, Giani G, Holle R, Koenig W, Lowel H, Meisinger C,(2006). Prevalence of the metabolic syndrome in the elderly population according to IDF, WHO and NCEP definitions and associations with Creactive protein: the KORA Survey 2000. Diabetes Care, 29:461-466.

Smith-Miller CA, (2004). Is watching television making kids fat? Fighting childhood obesity with the push of a button. Am J Nurs, 104:13.

Tumer N, Yalçinkaya F, Ince E, Ekim M, Köse K, Cakar N, Kara N, Ozkaya N, Ensari C, Onder S, (1999). Blood pressure nomograms for children and adolescents in Turkey. PediatrNephrol, 13:438-443.

Viner RM, Segal TY, Lichtarowicz-Krynska E, Hindmarsh P, (2005). Prevalence of the insulin resistance syndrome in obesity. Arch Dis Child, 90:10-14.

Weiss R, Dziura J, Burgert TS, Tamborlane WV, Taksali SE, Yeckel CW, Allen K, Lopes M, Savoye M, Morrison J, Sherwin RS, Caprio S, (2004). Obesity and the metabolic syndrome in children and adolescents. $N$ Engl $\mathrm{J}$ Med, 350:2362-2374,

Whitaker RC, Orzol SM, (2006). Obesity among US urban preschool children: relationships to race, ethnicity, and socioeconomic status. Arch PediatrAdolesc Med, 160(6): 578-84.

White MA, O'Neil PM, Kolotkin RL, Byrne TK (2004). Gender, race, and obesity-related quality of life at extreme levels of obesity. Obes Res, 12(6):949-55.

Yasar Sen \&Nurgun Kandemir \& AyferAlikasifoglu\&Nazli Gonc\& AlevOzon, (2008). Prevalence and risk factors of 
metabolic syndrome in obese children and adolescents: the role of the severity of obesity. Eur J Pediatr, 167: 11831189.
Zimmet P, Alberti G, Kaufman F, Tajima N, Silink M, Arslanian S, Wong G, Bennett P, Shaw J, Caprio S, (2007). International Diabetes Federation Task Force on Epidemiology and Prevention of Diabetes- The metabolic syndrome in children and adolescents. Lancet, 369:2059206.

\section{How to cite this article:}

Gupta Vani et al.2017, Presence and Risk Factors of Metabolic Syndrome Determinants In Indian Obese Children And Adolescents: According To National Cholesterol Education Program (Ncep) (Atpiii) Criteria. Int J Recent Sci Res. 8(3), pp.16180-16186.DOI: http://dx.doi.org/10.24327/ijrsr.2017.0803.0093 